\title{
Dr. Charles Leslie MacAdams
}

\author{
Alexander J. Gregory, MD
}

Received: 24 May 2016/Accepted: 31 May 2016/Published online: 7 June 2016

(C) Canadian Anesthesiologists' Society 2016

It is with heavy hearts that we announce the loss of our friend and colleague, Dr. Charles Leslie MacAdams. Dr. MacAdams, or "Charlie" as most of us knew him, passed away May 11, 2016 while on a medical education and mountaineering trip to the Himalayas. Following a successful $7000 \mathrm{~m}$ group ascent to the North Col, on the Tibetan side of Mt. Everest, Charlie was found in his tent the next morning, having passed away peacefully in his sleep.

Charles Leslie MacAdams was born on September 28, 1954 in Vancouver. Following his graduation with a Bachelor of Science in Human Physiology with Honours (1976), he went on to pursue his Doctor of Medicine degree (1982), both of which were attained at the University of British Columbia. Having completed a Family Medicine residency and rotating internship in Regina, Saskatchewan (1982-84) he returned west to the province of Alberta where he finished his residency in anesthesia in Calgary (1984-87). His subspecialty training in Cardiac Anesthesia took place at St. Boniface Hospital, University of Manitoba (1988). He subsequently resumed his practice as a Clinical Associate Professor in Anesthesia at the University of Calgary for the remainder of his professional career.

Charlie's career was highlighted by his enormous contributions to the field of anesthesiology. In addition to providing state-of-the-art clinical care, he was heavily involved in other aspects of academic medicine. A winner of the Canadian Anesthesiologists' Society Clinical Teacher Award (1998) and multiple local teaching

\footnotetext{
A. J. Gregory, MD (
}

Department of Anesthesia, Foothills Medical Centre, Calgary, AB, Canada

e-mail: alex.gregory@albertahealthservices.ca awards, he was highly regarded as an educator. His love for teaching had no borders as Charlie was very active in international education, donating personal time and funds to support anesthesia training in developing countries. Particularly fond of the peaks and the people of Nepal, he

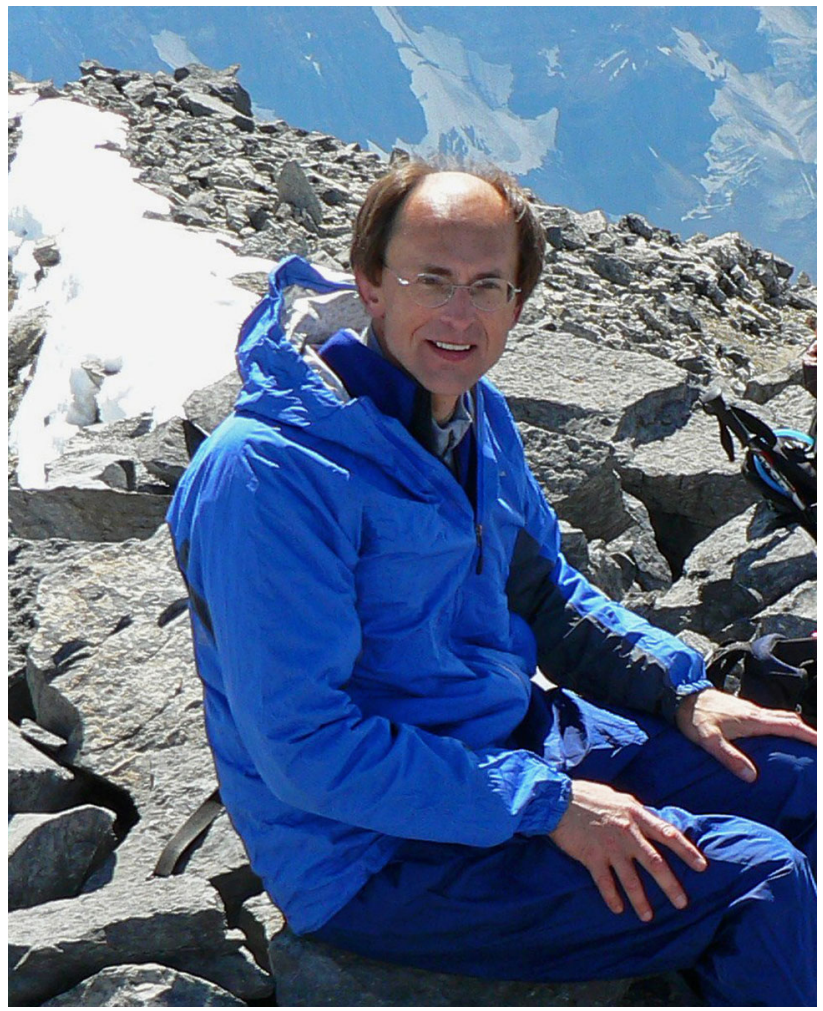

Figure Charlie MacAdams on Mt. Temple, Banff National Park, Alberta, Canada, in August 2007. This was one of Charlie's favorite peaks where he often took friends and operating room colleagues to the top. 
spent significant time teaching in local hospitals as well as sponsoring Nepalese physicians to travel to Canada for further training. This resulted in the formation of a cardiac anesthesia service at the Tribhuvan University Institute of Medicine in Kathmandu, an achievement made possible only by Charlie's efforts. Clinical research was always important to Charlie and culminated in a long list of peerreviewed publications, including several landmark trials. Over the past decade, he dedicated much of his research and administrative energies to optimizing transfusion practice and blood conservation strategies.

Dr. Charles MacAdams was a highly regarded, wellrespected member of the medical profession. Even more so, however, he carried himself with integrity and always fought for what he believed in. His career-long dedication has left behind many physicians, hospital staff, and patients with an unexpected void that will be impossible to fill. We will all miss him dearly.

His family wishes that any donations in Charlie's name please be made to either the Sir Edmund Hillary Foundation of Canada (http://thesiredmundhillaryfoundation.ca) or the Canadian Sudden Arrhythmia Death Syndrome Foundation (https://www.sads.ca/).

Conflict of interest None declared.

Editorial responsibility This submission was handled by Dr. Hilary P. Grocott, Editor-in-Chief, Canadian Journal of Anesthesia. 